CIVIL AND ENVIRONMENTAL ENGINEERING REPORTS

E- ISSN 2450-8594

CEER 2020; 30 (2): 0105-0132

DOI: $10.2478 /$ ceer-2020-0023

Original Research Article

\title{
UNDRAINED SHEAR AND PORE SPACE CHARACTERISTICS OF TREATED LOOSE SANDS WITH LIME-ACTIVATED ZEOLITE IN SATURATED SETTINGS
}

\author{
Babak JAMHIRI ${ }^{1,2 *}$, Mohammad Siroos PAKBAZ ${ }^{2}$ \\ ${ }^{1}$ State Key Laboratory of Ocean Engineering, Shanghai Jiao Tong University, China \\ ${ }^{2}$ Department of Civil Engineering, Shahid Chamran University, Iran
}

\begin{abstract}
This research investigates the mechanical behavior of artificially cemented sandy soils formed by lime alkali activation of natural zeolite under saturation settings. In order to verify the bar capability of cemented sands with this new method, an analysis of the undrained shear strength of the soil with pore water pressure ratio measurements was performed from the interpretation of the results of unconfined compression tests. The effect of zeolite-lime blend on treated sands was also visualized by scanning electron microscopy. For the studied soils, it was concluded from the unconfined compression stress values that the soil is fully capable of withstanding compressions due to overburden pressure. Additionally, this study seeks to evaluate the effect of the void ratio on the pore space and undrained shear strength. The results showed that pore water B-ratio increases with the decrease of the void ratio. Moreover, with the increase of zeolite content, confining pressure, and curing age, the peak failure strength increases. The results indicated a promising consistency of treated samples with lime and zeolite under various values of undrained shearing and B-ratios, making this method an ideal treatment for loose sand deposits.
\end{abstract}

Keywords: lime alkali activation, compressive strength, shear strength, void ratio, pore water pressure, B-ratio

${ }^{*}$ Corresponding author: State Key Laboratory of Ocean Engineering, Shanghai Jiao Tong University, Shanghai 200240, China, email: Babak.Jamhiri@sjtu.edu.cn 


\section{INTRODUCTION}

The majority of experiments on zeolite treated soils are conducted under a hypothesis that soils treated with zeolite are capable of catering for contamination upon sound chemical settings. [1, 2, 3], Nevertheless, the conditions where most of these treated soils are utilized is in aqueous environments and undrained conditions, where soils are in continuous contact with excess pore fluid pressure and prevented from water dissipation. Saturated sands in aqueous environments are potentially susceptible to water content fluctuations. When subjected to cyclic loadings, hydrous sands unable to drain will develop excess pore pressure, ending up with major shear-strength reductions and corresponding total failure which can lead to major disasters such as liquefaction. Measurement of the induced excess pressure within the pores, while necessary for interpreting material behavior in terms of the effective stress, is technically demanding since soils act indecisively when they become fully or partly saturated under loading [4, 5]. Measurement of the induced pore pressure response often described by the pore-pressure B-ratio is a function of pore space characteristics [6]. While the B-ratio represents the proportion of an increment in pore water pressure to the corresponding increment in cell pressure in undrained conditions, it cannot account for the variations in void ratio up to full saturation of pore space. Additionally, the introduction of stabilizing agents to the matrix structure alters the pore space's sole dependence on developed saturation and corresponding changes in void ratio. This also leads to a coupled response due to the degree of stabilization which signifies the need to comprehend the complexity of pore space developments in stabilized sandy soils. Therefore, to characterize the pore space it is required to include the coupled effect of variations of void ratio due to developed saturation while accounting for the effect of stabilization by considering the degree of pozzolanic reactions over various curing ages.

Furthermore, introducing new multipurpose material to encompass the coupled effect of pozzolanic cementation while facilitating the development of saturation of pore space is essential. Loose sands could be treated by lime-activated zeolite to create cementing particles. The term "activation" arises from the fact that zeolites are usually suggested for use in the treatment of clayey soils owing to their high reaction activity. Zeolites are naturally occurring pozzolans with a honeycomb structure having a high water demand, higher absorption rate, and high specific surface area, which when compared to mixtures with other pozzolans such as fly ash, enables them to be incorporated in the stabilization of saturated sand deposits [7, 8]. Their successful application in soil treatment depends heavily on the ignition of pozzolanic reactions. Clayey soils, rich in calcium oxides, are independent of activators when treated with zeolite. But fine granular soils such as loose sands require an inductor or so-called activator for 
their combined pozzolanic reactions such as with lime. Furthermore, as MolaAbasi et al. [9] showed, zeolites have a pozzolanic activity level between fly ash and silica fume and higher activity than non-zeolitic natural pozzolans and have a promising ability to amend fine granular soils. Zeolite's unique mechanical characteristics make it an ideal amending agent in soil treatment by incorporating its pozzolanic activity in creating cementing bonds while enjoying the benefits of its open framework for the absorption of water-soluble contaminations.

There are only a few studies available in terms of cement-zeolite treated soils catering for minor mechanical properties such as compressive strength or tensile strength while in those studies, zeolite was incorporated as a partial cement replacement $[9,10]$ and the remainder accentuate zeolite use in cement technology and geo-polymers [11, 12]. As a result of extensive literature research, it is apparent that no previous studies have sought to comprehend the effect of inclusion of lime activated-zeolite blends on treated sands, whether in terms of undrained shear resistance or induced pore water pressure or both, and available studies have only investigated lime-zeolite blends in mortars or only catered for the physio-mechanical properties of stabilized soils such as compressive strength and the rate of hydration in the concept of Arrhenius theory $[9,10,13,14,15]$.

Thus, the aim of this study is to first verify the reliability of the treatment of sands with lime-activated-zeolite (hereinafter referred to as "zeolite-lime") by interpretation of UCS results given the experimental condition at hand. Secondly, the study aims to characterize the pore space parameters such as void ratio and B-ratio of the treated soil by a series of triaxial undrained unconsolidated tests (UU) to ascertain the effects of the void ratio, zeolite content, and confining pressure over curing ages on the consistency of treated loose sands. Consequently, in this study, the ability of zeolite-lime treated sands to withstand induced pore water pressure while subjected to combined compressive and shearing forces in aqueous systems is precisely evaluated.

\section{MATERIALS AND EXPERIMENTAL PROGRAM}

\section{Materials:}

Clean and uniform quartz sand with sub-rounded to sub-angular particles reminiscent of those prevailing in aqueous systems was used as the parent soil. The results of the soil characterization tests are shown in Table 1, and the grainsize distribution curve of sand and Laser particle size analysis of zeolite is shown in Fig. 1. This soil is classified as poorly graded sand according to the Unified Soil Classification System. To produce acceptable fineness, all used zeolites were micronized by high energy ball milling. Zeolite of clinoptilolite 
origin was used in this study and the elemental composition of zeolite provided by the X-ray fluorescence (XRF) method, is shown in Table 2. Conventional dry hydrated lime $\left(\mathrm{Ca}(\mathrm{OH})_{2}\right)$ with a mean particle size of $2 \mu \mathrm{m}$ and a specific gravity of 2.34 was used as the binding agent. For the characterization tests, distilled water was used, and for molding of specimens and the other tests, tap water was used.

Table 1. Physical and mechanical characteristics of studied sand

\begin{tabular}{ll}
\hline Soil Property & Amount \\
\hline $\mathrm{C}_{\mathrm{u}}$ & 2.22 \\
\hline $\mathrm{C}_{\mathrm{c}}$ & 1.42 \\
\hline $\mathrm{D}_{10}$ & 0.09 \\
\hline $\mathrm{D}_{30}$ & 0.16 \\
\hline $\mathrm{D}_{60}$ & 0.2 \\
\hline Soil Name & $\mathrm{SP}$ \\
\hline Specific Gravity & 2.65 \\
\hline Optimum Moisture Content $(\%)$ & 15.6 \\
\hline Maximum Dry Density $\left(\mathrm{KN} / \mathrm{m}^{3}\right)$ & 15.77 \\
\hline Cohesion Intercept $(\mathrm{kPa})$ & 0.2 \\
\hline Internal Friction Angle $($ Degree) & 30 \\
\hline
\end{tabular}

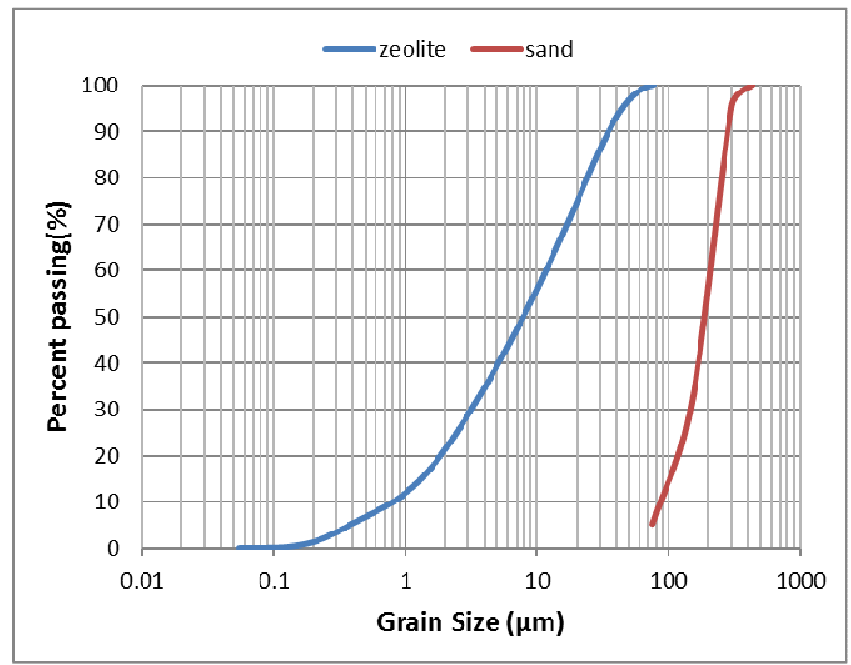

Fig. 1. Grain size distribution of studied sand and Laser Particle Size distribution curve of zeolite used 
UNDRAINED SHEAR AND PORE SPACE CHARACTERISTICS OF TREATED LOOSE 109 SANDS WITH LIME-ACTIVATED ZEOLITE IN SATURATED SETTINGS

Table 2. Elemental composition of zeolite (Clinoptilolite $\mathrm{k}^{+}$rich) obtained by X-ray fluorescence (XRF)

\begin{tabular}{cccc}
\hline Ingredient & Amounts(\%) & Ingredient & Amounts(\%) \\
\hline $\mathrm{SiO}_{2}$ & 66.5 & $\mathrm{~K}_{2} \mathrm{O}$ & 3.12 \\
$\mathrm{Al}_{2} \mathrm{O}_{3}$ & 11.81 & $\mathrm{P}_{2} \mathrm{O}_{5}$ & 0.01 \\
$\mathrm{Fe}_{2} \mathrm{O}_{3}$ & 1.3 & $\mathrm{MnO}$ & 0.04 \\
$\mathrm{CaO}$ & 3.11 & $\mathrm{TiO}_{2}$ & 0.21 \\
$\mathrm{MgO}$ & 0.72 & L.O.I & 12.05 \\
$\mathrm{Na}_{2} \mathrm{O}$ & 2.01 & & \\
\hline
\end{tabular}

L.O.I: $\overline{\text { Loss on ignition of volatile materials and hydrates at } 1000^{\circ} \mathrm{C}}$

\section{Molding and Curing of Specimens:}

The sand and zeolite were mixed carefully to reach a homogeneous state before lime was added. Some authors believe the increase in strength depends on particle size distribution and total particle surface area [16]. To reduce the grain size distribution dispersion, zeolites with the same particle size and specific surface area were used. The dry batch was then activated with hydrated lime until there was no separate particle visible. Finally, water amounts from the optimum moisture content result of the standard Proctor test were added, and the wet batch was again mixed properly to reach uniformity so that the mixing procedure lasted no longer than 30 minutes. In order to minimize the pore space non-uniformities within the specimens, an undercompaction procedure was employed. The advantages of the undercompaction procedure are that it uses the same type of compaction energy used in the field, and it promises consistent and repeatable results with minimal particle segregation.

Then, specimens were prepared to a target relative density by placing soil in layers and compacting each layer with a small tamper. The samples were prepared with a maximum dry unit weight varying from $15.6 \mathrm{kN} / \mathrm{m}^{3}$ to 16.5 $\mathrm{kN} / \mathrm{m}^{3}$ at a water content varying from $11.5 \%$ to $13.5 \%$. The molds were $77 \mathrm{~mm}$ in height and $35 \mathrm{~mm}$ in diameter and the entire preparation procedure lasted no longer than one hour. The molds with the samples in place were then sealed in plastic bags and placed in a humid room at $90 \%$ humidity and $20^{\circ} \pm 1{ }^{\circ} \mathrm{C}$ temperature. The reason for such a low curing temperature is that zeolite-lime mixtures have a shorter initial and final setting time than that of the plain mixtures [4]. Also, it should be noted that early stiffening of zeolite mortars at relatively high temperatures can lead to cracking and delamination, and residue in these cracks could lead to a subsequent weakening of specimens under triaxial loading. Thus, it is recommended that any optimized binding dosage obtained under laboratory conditions should conform with the in-situ ambient temperature and any modifications should be made prior to the application of stabilization plans. 


\section{Experimental program:}

The experimental program was carried out in three parts. First, the geotechnical properties of the studied soil and zeolite were characterized. Then, a series of unconfined compression (UC) tests for zeolite-lime blended specimens were carried out to determine the compressive strength of treated samples and the following optimized percentage of lime to be incorporated. According to Consoli et al. [17], a small portion of lime is enough to generate a significant rise in strength. Thus, four different lime percentages were used in this part, with the minimum amount of lime set at $3 \%$ of the mass of dry soil $[17,18,19$, 20]. The adopted zeolite percentages were chosen based on a few pertinent studies. Among those studies, researchers have tested zeolite additives in cement systems by studying the rate of hydration in blended cement containing natural zeolite. Nagrockiene and Girskas [21] concluded that substitution of up to $10 \%$ of cement with natural zeolite increases the compressive strength. Tydlitát et al. [22] further elaborated that the replacement of portland cement with an amount of $10 \%$ by mass of natural zeolite can be considered as the limit for its effective use. Above this limit, a substantial part of the zeolite does not directly participate in the hydration process and plays the role of a fine filler instead, this is seemingly in direct contrast to recent results in sandy soil stabilization presented by MolaAbasi et al. [10,] who evaluated the UCS of zeolite-cementsand mixtures and showed that UCS values of samples substantially enhanced by increasing zeolite replacement to cement content to an optimum value of $30 \%$, at which point the variation of UCS values remained approximately constant with increasing sample porosity. Although zeolite incorporation in cement technology promises sound feasibility, no certain zeolite percentage could be adopted as the optimum amount for lime incorporation in soil stabilization and this uncertainty further highlights the importance of optimizations in the zeolite-lime activation procedure.

Aiming at a generalization of the evidence produced by the present research, and in order to determine the optimized amount of lime as well as the validation of data reported by other investigators, three different percentage amounts of zeolite, i.e., $8 \%, 10 \%$, and $12 \%$ by the weight of the parent soil were adopted to be tested by UC tests [23, 24, 25]. Finally, a series of UU triaxial tests were carried out to investigate the undrained shear parameters, including B-ratio and the effects of void ratio on developed shear strength and the induced pore pressure. It is to be emphasized that, after lime optimization for activation of zeolite for pozzolanic reactions by UC tests, during UU triaxial tests, the optimized lime content was kept constant and various amounts of zeolite were also employed to determine the optimum zeolite content. The regulations and procedures regarding both series of tests will be given in the following paragraphs. 


\section{Unconfined Compression (UC) test procedure:}

UC tests are well-known for verification of the effectiveness of stabilization with lime or to access the importance of influencing factors on the strength of lime-treated soils. Therefore, following curing times of 7 and 28 days, the hardened samples were subjected to UC tests. Observed UCS corresponds to the maximum strain during compression and the UC tests were performed in accordance with ASTM D-2166 (2016). Accordingly, stiff or brittle materials that exhibit small deformations at failure should be tested at a lower rate of strain, and loading rate should be set to approximately 0.5 to $2 \% \mathrm{~mm} / \mathrm{min}$. Hence, the rate of displacement was adopted to be $0.75 \mathrm{~mm} / \mathrm{min}$ to facilitate the measurement of any abrupt failure. The tests were run until failure and not a specific deformation because the materials were assumed to be brittle and, accordingly, no definite deformation limit such as strain rate could be set. To minimize the scatter and error in the results, a minimum of three specimens were tested for each type of mixture, and these three tests were performed on average. However, the reproducibility tests showed both reliable and repeatable results across the testing program.

\section{Undrained Unconsolidated triaxial (UU) test procedure:}

The most common issue in saturated sand deposits is failure under rapid undrained shearing, which prohibits drainage causing catastrophic failures induced for example by liquefaction $[4,26]$. In order to validate the shear resistance of stabilized soils subjected to undrained shearing, the UU triaxial tests were performed on samples with the optimized lime containing $8 \%, 10 \%$, $12 \%$, and $14 \%$ zeolite according to the ASTM D 2850 (2015) with deformation controlled under a $0.75 \mathrm{~mm} / \mathrm{min}$ strain rate. Molded samples were prepared and cured by a similar procedure to the unconfined compression test specimens. Samples were placed in triaxial cell chambers and became saturated by a combination of back-pressure and vacuum procedure to conduct B-ratio and following saturation measurements.

Practically, the B-ratio test is performed by closing the drainage valve, increasing the cell pressure by a sufficient amount $\left(\Delta \sigma_{3}=200 \mathrm{kPa}\right)$ to allow determination of a reasonably accurate value of B-ratio, measuring $\Delta \mathrm{u}$, and calculating the value of $\mathrm{B}=\left(\Delta \mathrm{u} / \Delta \sigma_{3}\right)$. During the test, simultaneous measurements of $\Delta \sigma \mathrm{d}$ and $\Delta \mathrm{ud}$ were made and testing equipment was calibrated and made capable of measuring the variations of confining pressure throughout specimen saturation and loading. A more detailed discussion will be given when comparing the results of measured B-ratios in this study with the experimental results of previous studies. Subsequent triaxial tests were performed under 0.5, 1 , and $1.50 \mathrm{~kg} / \mathrm{cm}^{2}$ of confining de-aired water cell pressure. Similarly to the UC 
tests, the tests were run until failure and not a specific deformation, and then the averaged results were reported.

\section{RESULTS AND DISCUSSIONS}

\section{Unconfined Compression test:}

The UCS variations with the amount of zeolite and lime are shown in Fig. 2 and 3 for the two distinct curing periods of 7 and 28 days, respectively. In general, all treated samples with zeolite-lime percentages outlined by letters $\mathrm{Z}$ and $\mathrm{L}$, respectively, showed improved compressive strength due mainly to the formation of the cemented compounds in treated soils with the progress of pozzolanic reactions, which led to the increase in bonding and interlocking forces between soil particles, as previously reported by Rao and Rajasekaran [27]. As shown in Fig. 2, after 7 days, cured samples with similar lime content showed a persistent increase in the compressive strength as zeolite content increased; while samples with the highest strength reached failure at nearly lower axial strains.

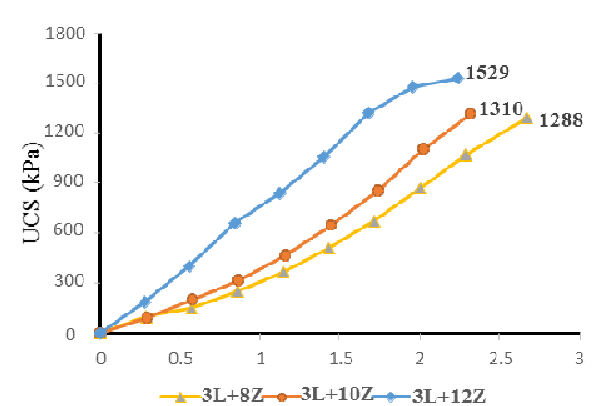

(a)

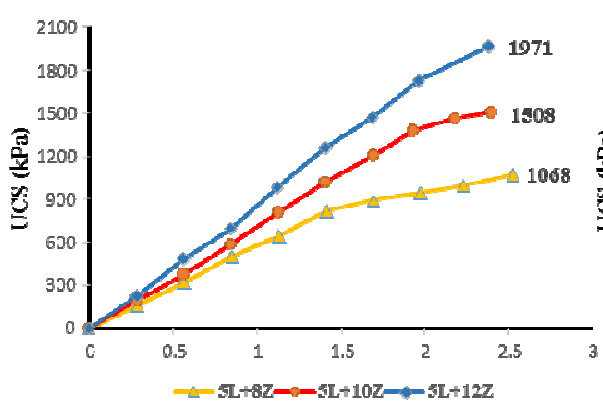

(C)

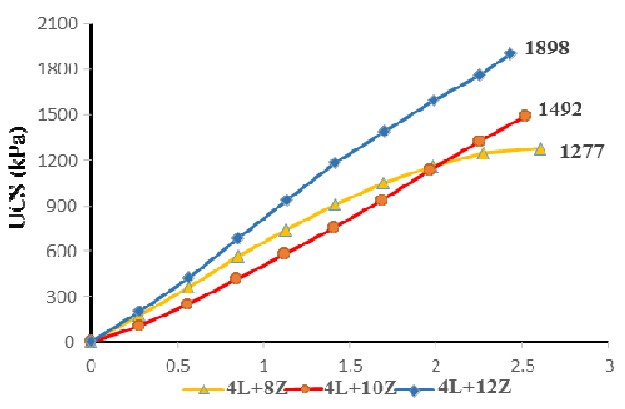

(b)

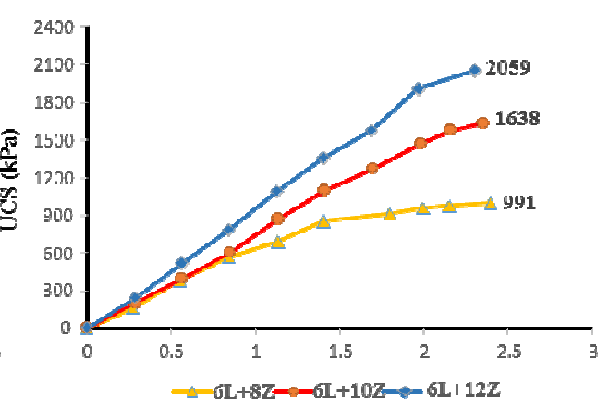

(d)

Fig. 2. The Unconfined Compressive Strength (UCS) variations of zeolite-lime treated samples cured for 7 days 
The results in Fig. 3(a)-3(c) indicate that 28-days cured samples containing 3\% and $5 \%$ lime projected a similar growth as those of 7-days cured samples and show a constant increase in compressive strength with the increase of zeolite content. However, for samples with $4 \%$ and $6 \%$ lime, as shown in Figs. 3(b)$3(d)$, the maximum compressive strength oppositely belongs to the samples with less zeolite. Having these contradictory observations at hand and comparing the results of 7 and 28 days cured samples indicates that the main reason for these differences could be related to the imbalance of the incorporation of zeolite and lime into the pozzolanic reaction process. This leads to an uneven distribution of cemented particles and the reduction of final strength [20, 28]. For example, in samples with 4\% lime, as shown in Fig. 3(b), available calcium hydroxide was not enough for the pozzolanic reactions (inadequate alkalinity) to progress, and in samples with $6 \%$ lime, as shown in Fig. 4(d), zeolite was insufficient to consume excess lime (high alkalinity).

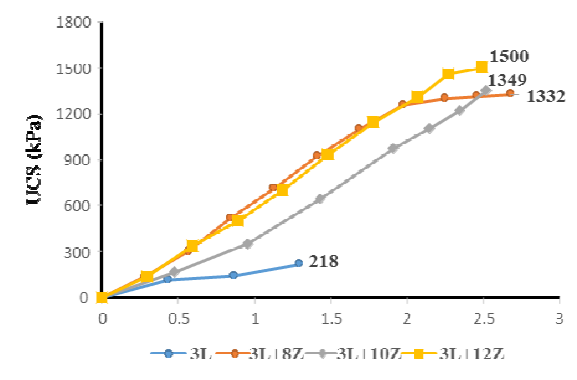

(a)

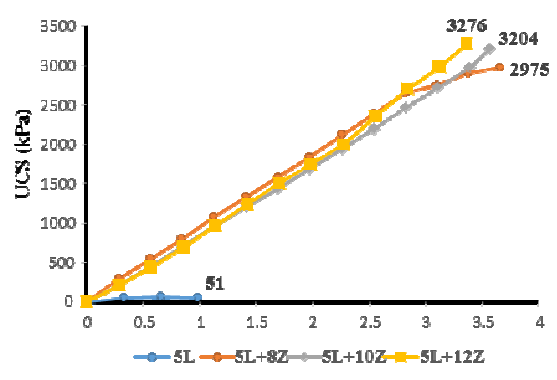

(c)

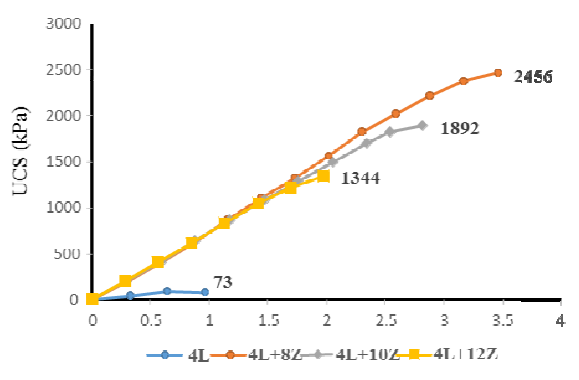

(b)

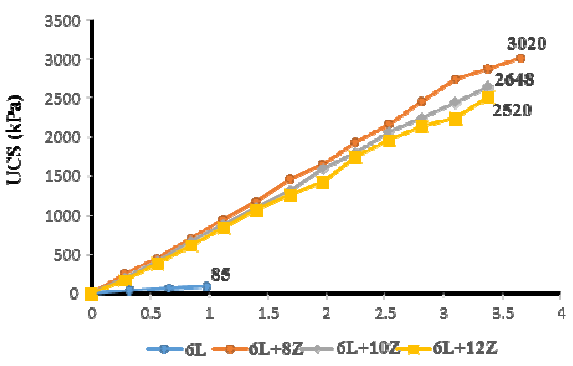

(d)

Figure 3: The Unconfined Compressive Strength (UCS) variations of zeolite-lime treated samples cured for 28 days 
In other words, as lime percentage increased, the $\mathrm{pH}$ increased accordingly and strongly influenced the early reactivity [29]. Therefore, calcium hydroxide and alkalinity, compared to the other percentages, remained high over the entire curing period and a hospitable $\mathrm{pH}$ environment for the progress of pozzolanic reactions was not satisfied. The soil-pH response of various zeolite percentages with lime compared to the plain soil with lime only at different curing ages is reported in Fig. 4. It is obvious that as time passes, the $\mathrm{pH}$ of zeolite-based samples increases more than that of samples with lime only. This rate of increase is more evident at higher lime contents due to the higher rate of zeolite activation with more consumable lime.

Another reason for the absence of a similar trend in the strength development of samples with $4 \%$ and $6 \%$ compared to those with $3 \%$ and $5 \%$ lime is the moisture loss during hydration of calcium hydroxide, especially with respect to higher alkalinity [7, 30]. Drying and carbonation of calcium aluminate prevent the course of lime-pozzolan reactions and they will limit the achievement of more strength; for example, samples including $6 \%$ lime first showed a rapid increase in strength which then grew slower over 28 days of curing (Figs. 2(d)$3(d)$ ). Similarly to hydraulic lime mortars, hardening of cemented samples containing $6 \%$ lime occurs because of the pozzolanic reactions as well as hydration reactions which mainly occur at high humidity and are slowed down or even inhibited by lower moisture content because of excessive lime presence. Moreover, alkali concentration increased as the hydration reactions consumed free water. Consequently, the required $\mathrm{pH}$ environment for reactions became unsuitable. As stated by Thomas et al. [30], the increase of zeolite addition in the samples slightly increases the consumption of lime, but simultaneously promotes the transformation of calcium aluminate silicate (C-A-S) phases into calcium aluminate hydrate $(\mathrm{C}-\mathrm{A}-\mathrm{H})$ and calcium silicate hydrate $(\mathrm{C}-\mathrm{S}-\mathrm{H})$ in the final solidification stage, as shown in Fig. 5. The formation of the carbonated phases apparently resulted in a decrease of compressive strength of the samples containing 6\% lime compared to those containing 5\% lime, as shown in Figs. 3(c)-3(d). 


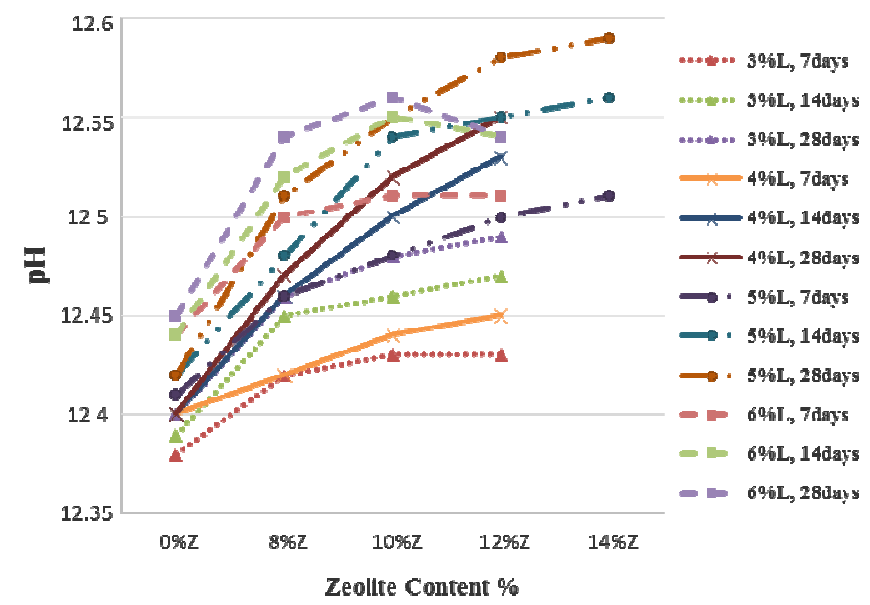

Fig. 4. The soil-pH response of various zeolite (Z) with lime (L) mixes compared to plain sand and lime at 7,14 , and 28 days of curing

It is worth noting that the UCS of samples without zeolite at 7 days of curing could not be analyzed because the specimens did not hold their consistency upon mold removal, demonstrating impractical efforts in sand treatment with plain lime. Considering the granular nature of the soil, it was assumed that limetreated specimens with no zeolite have a UCS close to zero in the early stages of curing, and only at the age of 28 days did cured samples show consistency upon removal from the molds, but they also showed a negligible strength, as shown in Fig. 3 (depicted in blue curves), with the highest UCS belonging to the samples with the least lime content, suggesting that lime treatment of granular soils with no binding agent has a deteriorating effect in bearing capacity. Finally, in the light of the UC tests, it can be seen that the optimum lime requirement for zeolite-lime treatment of loose sands is $5 \%$ given the experimental conditions in the current study.

\section{Unconsolidated undrained triaxial test:}

As can be seen in Fig. 5, after lime-activation of the zeolite and initiation of pozzolanic reactions, the microstructure of the treated sand will undergo a lot of changes. The plain pore space in the untreated sands now contains cemented bonds while the pozzolanic agent itself has both the ability of consuming water thorough lime activation and absorbing water in its open framework. This complex nature of the treated samples necessitates the measurement of pore pressure and the corresponding changes in the progress of undrained shear resistance. 

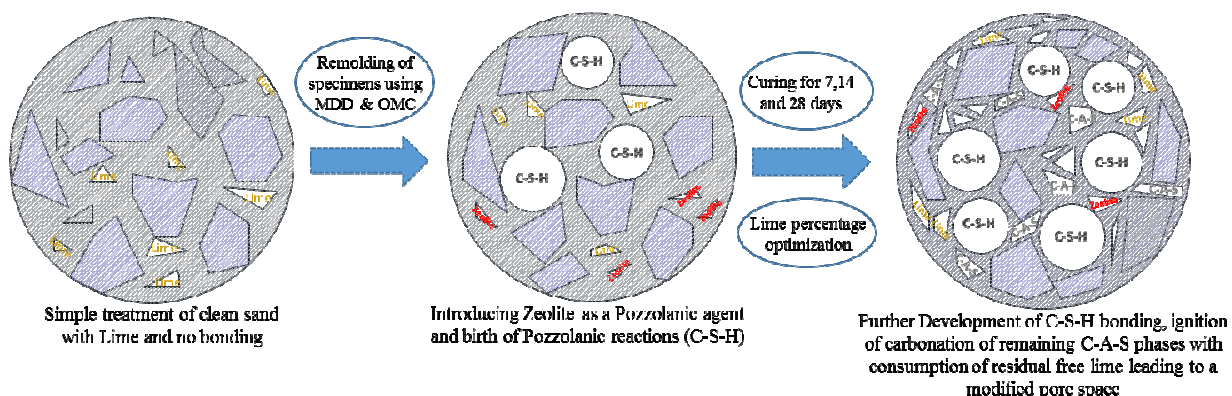

Fig. 5. Phase change in plain samples with and without lime after zeolite activation and pozzolanic reactions

For that reason, the UU stress-strain curves are depicted in Figs. 6, 7, and 8 for three distinct curing periods of 7, 14, and 28 days, respectively. In general, it is obvious that as the confining pressure increases, the associated peak shear stress also increases, and the peak resistance mobilizes in the majority of samples at axial strains of $1.5 \%$ to nearly $2 \%$.

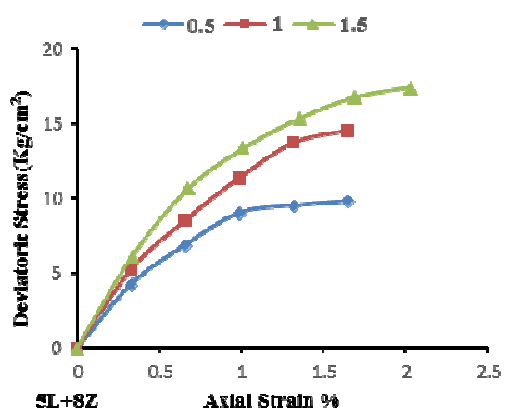

(a)

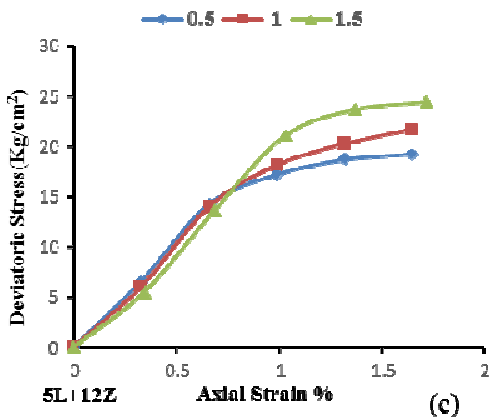

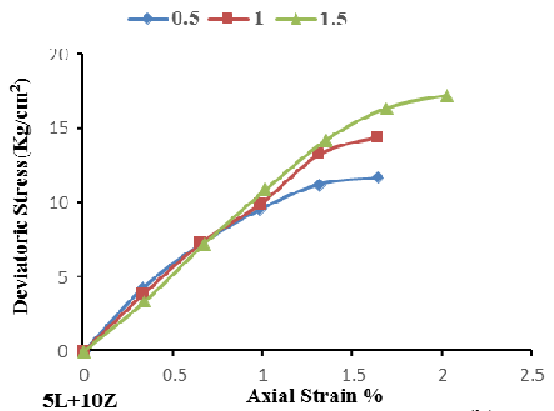

(b)

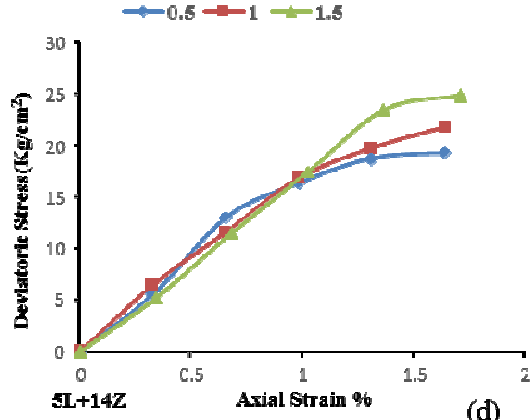

(d)

Fig. 6. The Undrained Unconsolidated (UU) stress-strain response of 7-days cured samples under 05,1 , and $1.5 \mathrm{~kg} / \mathrm{cm}^{2}$ confinement 
However, samples with $12 \%$ and $14 \%$ zeolite reached failure at less than $1.5 \%$ axial strain (Figs. 8(c)-8(d)) mainly due to the presence of more zeolite which led to a more cemented body with a rapid yet higher stress peak. Similar strain levels at failure for cement-treated Toyoura sands are also reported by Namikawa et al. [31]. The samples in the undrained tests shown in Figs. 6, 7, and 8 exposed strain-hardening behavior [32]; in other words, there were no clear drops and residual softening in strength, therefore, pronounced peaks (failure points) on the slopes of the curves are failure points of the samples.

The stress-strain behavior typically resembled that similar to sandy soils in a dense state. It is also evident from Figs. 6, 7, and 8 that at lower values of axial strain, the deviator stress increases almost linearly with the axial strain, this then changes into a slightly concave downward pattern, though at a much slower rate. This is perhaps due to the development of greater friction between the particles of the composite, making it difficult for the nearby particles to change their position rapidly from one point to another, which then leads to the improvement in the frictional resistance and slower rate of strain.

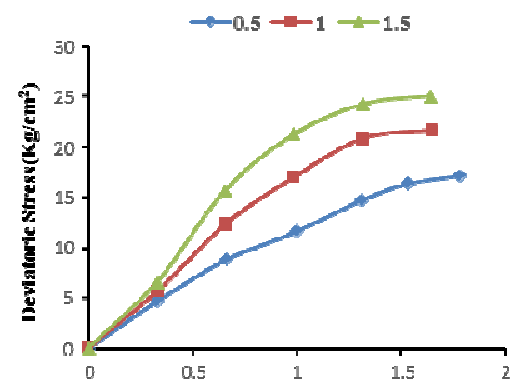

$\mathbf{5 L}+\mathbf{8} \mathbf{L}$

Artal Strain $\mathrm{o}_{\mathrm{n}}$
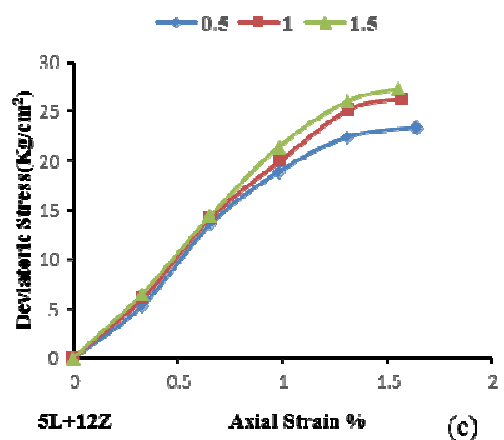

(c)

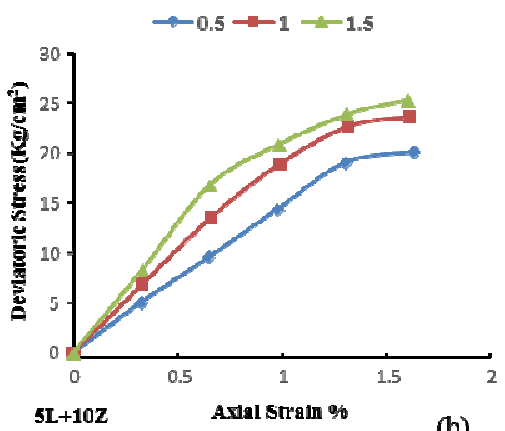

(b)

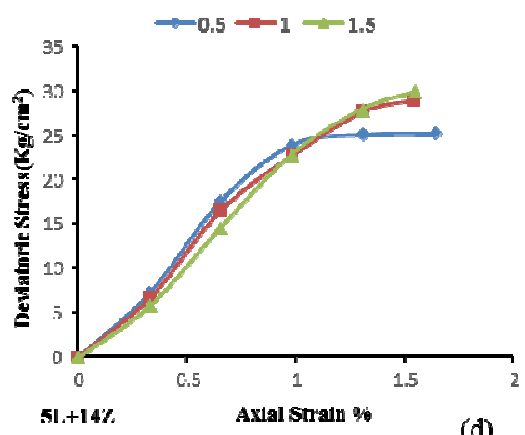

(d)

Fig. 7. The Undrained Unconsolidated (UU) stress-strain response of 14-days cured samples under 05,1 , and $1.5 \mathrm{~kg} / \mathrm{cm}^{2}$ confinement 
It is noteworthy that the effect of cementation is to produce aggregate interlocking that can be overcome by dilatancy, and it is also known that dilatancy at failure provides an extra component of shear strength [33], and as stated by Wang and Leung [34], cement bond breakage causes a strength reduction, but the associated dilatancy leads to a strength increase in cemented soils. Thus, the conclusion can be drawn that initiated suppression of dilatancy by undrained shearing results in the lack of a certain peak deviator stress due to a reduction in the corresponding pore-water pressure.

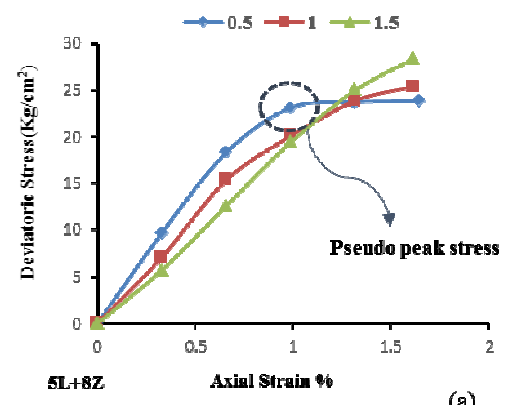

(a)

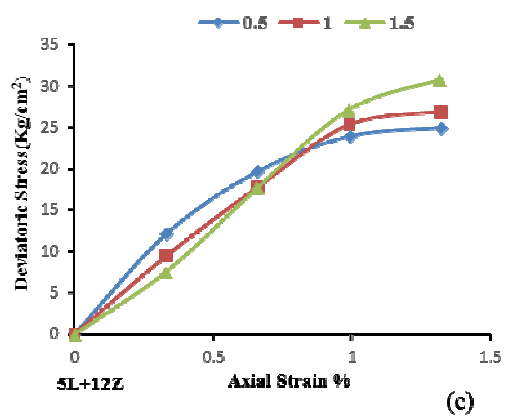

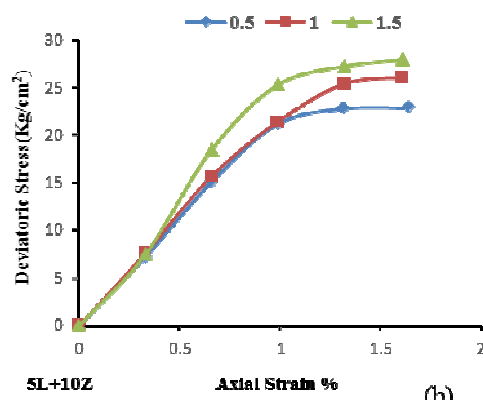

(b)

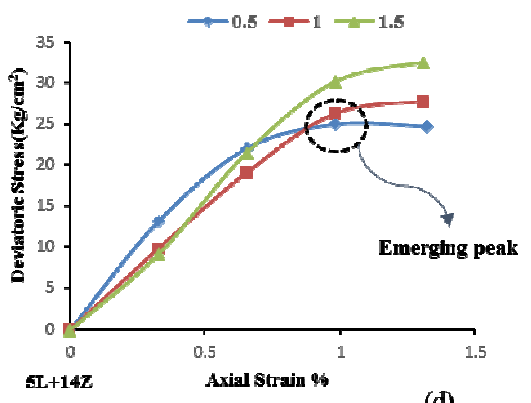

(d)

Fig. 8. The Undrained Unconsolidated (UU) stress-strain response of 28-days cured samples under 05,1 , and $1.5 \mathrm{~kg} / \mathrm{cm}^{2}$ confinement

As presented in Figs. 6 and 7, samples usually show no definite peak deviator stress, failure occurs abruptly, and this behavior is common in sandstones [35]. But taking a closer look, and with the maturation of the treated samples with the higher pozzolanic reactions, attention is drawn to a semi-concave end on the charts with lesser confinement, especially in Fig. 8(d). Seemingly, a modest peak emerges ascertaining a possible presence of residual strength only at lower confining pressures and when the highest zeolite content prevails. This interesting phenomenon adds to the complexity of the failure mechanism, 
indicating that aged treated samples could provide some residual strength even after reaching the highest shear strength while other peaks in prior strains as, for example, in Fig. 8(a) are a simple consequence of local softening or pseudo peak stress [36]. It should also be noted that this effect diminishes when the confining pressure increases and the entire shear resistance mobilizes under loading.

Comparing the results of UCS shown in Figs. 2 and 3 and the results of the UU triaxial tests presented in Figs 6, 7, and 8, a higher peak strength is indicated in UC tests in contrast to the values obtained by UU triaxial tests. Haeri et al. [37] and Hamidi and Haeri [38], who obtained similar results, reported that a brittle behavior exists in drained conditions when compared with similar undrained tests. This may be due to the concentration of excess pore pressure in the shear plane that is not present during UC tests. Moreover, similar higher peaks as those observed in the UC tests may also be caused by volume changes occurring during shearing [39], the water weakening effect on samples during undrained shearing $[40$,$] and possibly due to a higher sensitivity of undrained tests to shear$ localization.

Analysis of post-failure images, as can be seen in Fig. 9, indicated that all samples failed by shear localization with a single shear zone crossing each sample. Accordingly, in reference to Fig. 9, the shear bands referred to as the Coulomb direction are directed at $\pm\left(45^{\circ}+\varphi / 2\right)$ to the cap and base platen [41]. The evolution of loose sands into cemented compounds means that the resulting material at the end of the curing time has different properties to the primary loose sand and, according to the results presented in this paper, they present a behavior similar to sandstones. The results further demonstrated that the microcrack initiation occurred very close to the failure stress under low confining pressures, leading to a more brittle sudden failure, whereas, under higher confining pressures, failure occurred at relatively earlier stages of deviatoric loading due to the higher confining stress on the microcracks.

As shown in Figs. 7 and 8, under higher confining pressures, the samples reached failure at slightly lower axial strain, whereas, due to lack of full cementation, samples with 7 days of curing (Fig. 6) and under lower confining pressures reached failure at slightly lower axial strain. The UU shear strength corresponding to the samples without zeolite at all curing periods could not be experimentally determined as the specimens disintegrated during sample saturation in the triaxial cell before conducting the triaxial test. Finally, 
depending on the obtained results of the undrained shear tests under three confining pressures of 05,1 , and $1.5 \mathrm{~kg} / \mathrm{cm} 2$, Mohr failure circles were drawn, and the detailed results for the cohesion intercepts and the internal friction angles were listed in Table 3 .
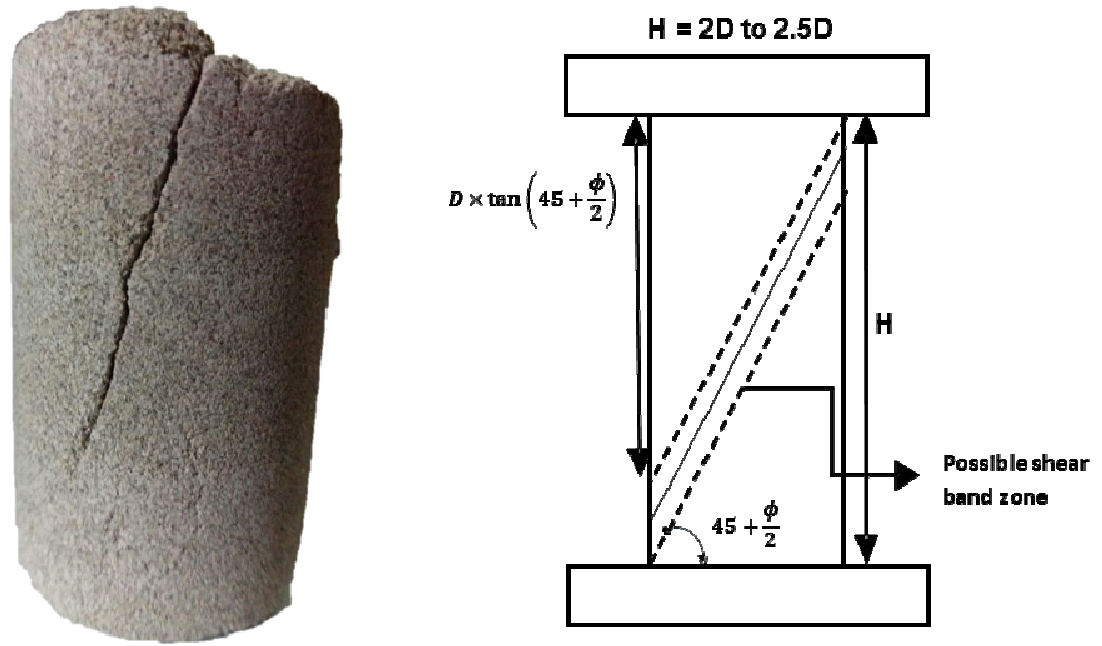

Fig. 9. Post-failure image of zeolite-lime treated sample with an apparent diagonal shear zone

Regarding the 7- and 14-days cured samples, an increase in zeolite content resulted in an initial decrease followed by a slight increase in internal friction angles, but 28-days cured samples showed an increase in internal friction angles and a decrease in cohesion with increasing zeolite amount. The reason for this is related to the higher pozzolanic reactivity of zeolite [42, 43, 44, 45], also, as mentioned previously, this could be because of the increase in slippage between sand particles due to extra lime at earlier ages of curing and breakage of strong cemented bonds at 28 days of curing. Similar observations to the current results in Table 3 were also reported by authors studying lime-treated sandy soils [46, 47]. As shown in Table 3, for different mixtures of lime and zeolite represented by capital letters $\mathrm{L}$ and $\mathrm{Z}$ respectively, the biggest internal friction angle acquired in the present study belonged to the mixture of $14 \%$ zeolite $\left(55.4^{\circ}\right)$, suggesting this to be the optimum amount of zeolite regarding shear strength. 
UNDRAINED SHEAR AND PORE SPACE CHARACTERISTICS OF TREATED LOOSE 121 SANDS WITH LIME-ACTIVATED ZEOLITE IN SATURATED SETTINGS

Table 3. Variation of cohesion intercepts and internal friction angles of artificially cemented samples at curing periods of 7,14 , and 28 days by UU tests results

\begin{tabular}{ccccccc}
\hline Curing age & \multicolumn{2}{c}{7 days } & \multicolumn{2}{c}{14 days } & \multicolumn{2}{c}{28 days } \\
\hline Type of Mixture & $\mathrm{C}(\mathrm{kPa})$ & $\varphi^{\circ}$ & $\mathrm{C}(\mathrm{kPa})$ & $\varphi^{\circ}$ & $\mathrm{C}(\mathrm{kPa})$ & $\varphi^{\circ}$ \\
\hline $\mathrm{S}+5 \% \mathrm{~L}^{*}+8 \% \mathrm{Z}^{*}$ & 98 & 53.2 & 235 & 52.9 & 357 & 48.5 \\
\hline $\mathrm{S}+5 \% \mathrm{~L}+10 \% \mathrm{Z}$ & 169 & 48.3 & 342 & 48.8 & 343 & 51.2 \\
\hline $\mathrm{S}+5 \% \mathrm{~L}+12 \% \mathrm{Z}$ & 354 & 44.3 & 402 & 47.6 & 326 & 53 \\
\hline $\mathrm{S}+5 \% \mathrm{~L}+14 \% \mathrm{Z}$ & 358 & 44.8 & 431 & 49 & 316 & 55.4 \\
\hline
\end{tabular}

Comparing the undrained shear strength parameters of internal friction angle and cohesion for cemented samples in Table 3 with those for untreated sand given in Table 1, an increase of 500 to about 2150 times in the cohesion intercept and 1.5 to 1.85 times in the angle of internal friction is recorded. According to Consoli et al. [48, 49], who studied sand stabilization with lime and fly ash and industrial waste by-products, internal friction angle values obtained in this study are higher. Although, results of both studies show improvement in terms of internal friction but greater improvement when zeolite is utilized, indicating promising prospects for zeolite-lime stabilization of loose sands.

\section{Analysis of the measured B-ratios:}

Tatsuoka et al. [50] showed that for loose sands, proving a good saturation requires the verification of a high B-ratio, while this requirement is less demanding for stiffer materials. So, the results of the measured B-ratios are presented in Table 4 regarding different lime and zeolite percentages indicated by capital L and Z, respectively. For very stiff or cemented soils, the value of B is expected to be less than unity, even for fully saturated specimens [51, 52]. It is, therefore, difficult to evaluate the degree of saturation on the basis of the Bratio test alone. Moreover, an intact or fissured microstructure has a significant impact on the value of B at non-zero differential pressures, for example, cracked sandstones apparently have a value of B near 0.6, while sandstones with low crack densities are expected to have values closer to 0.8 for non-zero differential pressures [53]. 
Table 4 suggests that as confining pressure increases over time, B-ratio decreases. Reduction in B-ratios results directly from two factors; firstly, pozzolanic reactions and the evolution of the soft soil into a rigid cemented body impervious to water penetration and, secondly, a reduction in B-ratio might result from declining bulk compressibility due to the closure of low aspect ratio microcracks that are highly compliant at low confining pressures or by the compression of relatively soft inter-granular contacts [54]. Additionally, Tufts which their original micro-structure altered into zeolite generally exhibit reduced B-ratios and bulk compressibilities during undrained loading, suggesting extra complications during saturation when their pozzolanic capabilities are being activated by alkali binders such as lime [55].

Table 4. Variation of pore pressure B-ratio with confining pressure at curing periods of 7,14 , and 28 days

\begin{tabular}{ccccccccccc}
\hline Curing Age & \multicolumn{4}{c}{7 days } & \multicolumn{4}{c}{14 days } & \multicolumn{2}{c}{28 days } \\
\hline $\begin{array}{c}\left(\mathrm{kg} / \mathrm{cm}^{2}\right) \\
\text { Pressure }\end{array}$ & 0.5 & 1 & 1.5 & 0.5 & 1 & 1.5 & 0.5 & 1 & 1.5 \\
\hline $\mathrm{S}+5 \% \mathrm{~L}+8 \% \mathrm{Z}$ & 0.91 & 0.9 & 0.9 & 0.88 & 0.87 & 0.87 & 0.84 & 0.84 & 0.83 \\
\hline $\mathrm{S}+5 \% \mathrm{~L}+10 \% \mathrm{Z}$ & 0.9 & 0.89 & 0.88 & 0.86 & 0.86 & 0.85 & 0.84 & 0.83 & 0.83 \\
\hline $\mathrm{S}+5 \% \mathrm{~L}+12 \% \mathrm{Z}$ & 0.88 & 0.88 & 0.87 & 0.85 & 0.85 & 0.84 & 0.83 & 0.82 & 0.82 \\
\hline $\mathrm{S}+5 \% \mathrm{~L}+14 \% \mathrm{Z}$ & 0.87 & 0.86 & 0.86 & 0.84 & 0.84 & 0.83 & 0.81 & 0.8 & 0.8 \\
\hline
\end{tabular}

Theoretically, the mixture of pore water and air can approximately be treated as an equivalent homogeneous pore fluid, completely filling the voids with a single pore pressure. Since the compressibility of water is negligible compared with that of the soil skeleton, at the early stage of curing, lack of sufficient cementation in samples containing more zeolite leads to a greater increase in the soil skeleton's compressibility and, as a result, the value of B consequently decreases. Additionally, regarding the length of curing and as the compressibility of cemented samples approaches the same order of magnitude as the compressibility of water during saturation, the open framework of zeolite that is gradually saturated with water diminishes and leads to a lesser B-ratio in longer curing periods.

Measured B-ratios in this study are near to those observed by Green and Wang [54] who measured $B$ values in the range of 0.95 to 1.0 for differential pressures below $1 \mathrm{MPa}$ for fully saturated Berea and Massillon sandstone. Fredrich et al. 
[55] also showed that in fully saturated zeolite sandstone, a B-ratio at near-zero applied confining minus-induced pore pressure is close to 0.9 and decreases systematically to approximately 0.7-0.8 at effective pressures of about $25 \mathrm{MPa}$. Namikawa et al. [31] studied cement-treated Toyoura sand by triaxial compression tests under confining pressures varying from 50 to $200 \mathrm{kPa}$. Bratios measured during their tests ranged from 0.8 to 0.95 for samples prepared with $4.5 \%$ cement and from 0.7 to 0.95 for samples prepared with $7 \%$ cement. This is in good agreement with the current results. However, in the present study, the cementing agent is a mixture of lime and zeolite. Moreover, these results indicate a robust consistency of zeolite-lime treated sands against induced pore water pressure under the applied saturation settings and make zeolite-lime a promising treatment by presenting both environmental and geotechnical advantages.

\section{Void ratio effect on pore space:}

Application of the void ratio is proven to be an appropriate tool to assess the developed cementation of stabilized sands by binding agents. To analyze the variations of void ratio over curing time and before undrained shearing, the void ratio of cemented samples was calculated from equation 1:

$$
e_{c}=\frac{\left(1+w_{t}\right) G_{s t} \gamma_{w}}{\gamma_{t}}-1
$$

where $e_{\mathrm{c}}$ is the after curing void ratio before the shearing process, $\mathrm{w}_{t}$ is the after curing water content, $G_{\mathrm{st}}$ is the after curing total specific gravity, $\gamma_{\mathrm{t}}$ is the after curing unit weight, and $\gamma_{\mathrm{w}}$ stands for unit weight of water. It should be noted that this void ratio represents the final condition of samples before shearing. This is unlike the isotropic consolidation stage in consolidated undrained triaxial testing in which volume change after the consolidation should be accounted for in the calculation of the void ratio [56].

The influence of deviatoric stress, curing age, and confining pressure on the void ratio is illustrated in Fig. 10(a). Hypothetically, it is assumed that in the early ages of curing, when soaked zeolite and lime are packed together, unoccupied pore spaces not taken up by pozzolanic by-products (calcium silicate hydrate or C-S-H) are composed of voids containing a mixture of air and free water whose sizes are determined by succeeding degrees of cementation. The amount of air and water occupancy of the voids is mainly dependent on the 
degree of saturation and air dissolution in water. So, as the B-ratio is also a function of degree of saturation and any presence of unconsumed water means available anhydrous particles and extra void space for further bonding, the increase of degree of saturation is equal to the increase with the B-ratio as well as the presence of a higher void ratio.

It is clear from Fig. 10(a) that void ratio increases with increasing B-ratio. But void ratio decreases over curing time due to further development of $\mathrm{C}-\mathrm{S}-\mathrm{H}$ bonds when a coarser mass of their reaction product is being produced by growing pozzolanic reactions. As highlighted in Fig. 10(b), with the increase of zeolite content under similar confining pressures, the difference between values of the void ratio in pore spaces is significant and exists over the entire curing ages. But, for samples with a similar zeolite content, the difference between the void ratios and peak deviatoric strengths becomes less significant over curing ages, especially for treated samples with $12 \%$ and $14 \%$ zeolite, when compared to those samples treated with $8 \%$ and $10 \%$, the increase in peak failure strength and void ratio is rather extreme across the length of curing age.
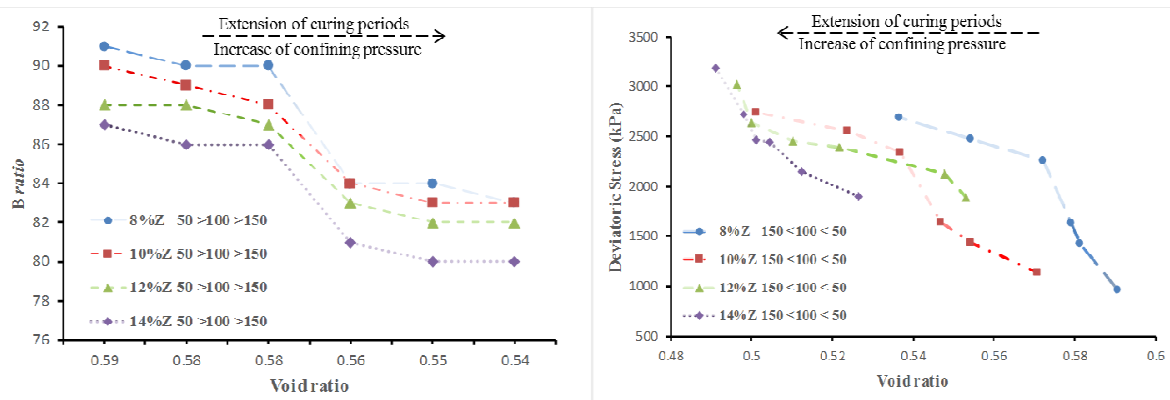

Fig. 10 (a) Influence of peak deviatoric stress, curing age, and confining pressures at 50, 100 , and $150 \mathrm{kPa}$ on B-ratio, (b) Variation of the void ratio at peak failure stress for samples containing zeolite over curing ages (Darker colors indicate 7 days and lighter colors indicate 28 days of curing)

\section{Scanning electron micrographs (SEM) analysis:}

SEM assists in determining the efficiency of treatment on morphology and contributes to assessing the C-S-H localization on sand particles. For the SEM analysis, at the specified curing time, a small amount of soil mass was taken from the cured sample, air dried, and broken into particles of sizes less than $0.075 \mathrm{~mm}$ by sieving before testing. The SEM technique was performed using an LEO $1455 \mathrm{VP}$ scanning electron microscope operating at $30 \mathrm{kV}$. The SEM micrographs of stabilized samples with $14 \%$ zeolite and $5 \%$ lime along with the 
SEM of plain sand with 5\% lime at the curing period of 28 days, magnified at 2 $\mu \mathrm{m}$, are shown in Figs. 11(a)-11(b), respectively. SEM analysis revealed that samples containing lime-activated zeolite have a denser microstructure with fewer macrospores, and products of the zeolite-lime blend, which are believed to be C-S-H gels, are edged with a flat surface and a crystalline shape. The SEM of lime-treated samples without zeolite is shown in Fig. 11(a), revealing a plain surface of sand particles which is intact with some minor coverage and separated lime particles, and showing a common axiom that granular material without fine content cannot be improved with lime. However, Fig. 11(b) enlightens the results of the current study by providing visual evidence of the solid performance of lime activation of zeolite for the overall improvement of loose sands. Zeolite-lime treated samples also clearly display a coarse soil matrix and inter-particle bridges, which are attributed to the pozzolanic C-S-H bonds.

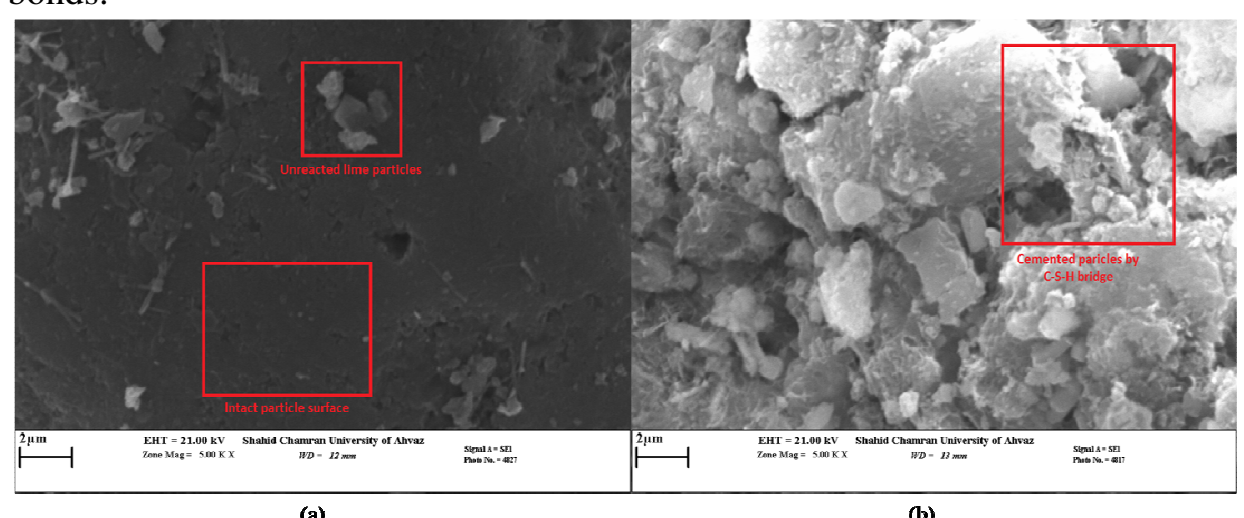

(a)

(b)

Figure 11: SEM analysis of samples at 28 days of curing (a) sample containing only $5 \%$ lime without zeolite incorporation (b) samples containing 5\% lime and 14\% zeolite incorporated

\section{CONCLUSIONS}

In order to provide a solid framework for a combined geo-mechanical sandy soil treatment with an eco-friendly blend of natural zeolite and lime, and to ascertain the consistency of treated samples against undrained shearing and induced pore water pressure in saturated settings, a series of UC and UU triaxial tests were carried out on treated loose sands with lime-activated zeolite, and the effects of variations in lime and zeolite content on UCS values, undrained shear strength, 
and B-ratios were studied. With the knowledge of the experimental evidence, the following conclusions can be drawn:

1. The stress-strain curves measured by means of the undrained triaxial test were brittle and the samples showed strain-hardening behavior, there were no clear drops and residual softening in peak strength, and the peak resistance mobilized at an axial strain of about $1.5 \%$ to nearly $2 \%$. However, only at lower confining pressures and when the highest zeolite content was utilized, did aged samples show an emerging residual strength.

2. As the confining stresses increased, B-ratio decreased due to the closure of low aspect-ratio pore spaces and microcracks and the compression of relatively soft intergranular contacts. Despite an increase in the induced pore water pressure and the appearance of diagonal shear localization, treated samples showed a high consistency against complete fragmentation.

3. At earlier ages of curing, due to the lack of sufficient cementation in samples containing more lime, an increase of compressibility of the soil skeleton led to a decrease of B-ratio, indicating that immature pozzolanic reactions could lead to inconsistencies and possible failure of treated samples under higher rates of pore water pressure.

4. With the extension of curing ages and increasing degree of cementation, the air voids compress with the increasing confinement and more cemented products fill the spaces occupied by water, so that the void ratio becomes relatively small resulting in a relatively low value of Bratio.

5. Samples with high zeolite content leave smaller unoccupied pores after cementation than samples with less zeolite, thus resulting in a lower void ratio in the hardened blend while showing higher peak failure strength.

6. The UCS values show higher peak strengths than similar results in UU triaxial tests, this might be due to a concentration of excess pore pressure in the shear plane, the water weakening effect, and the prone nature of undrained tests to shear localization.

7. All samples failed by shear localization with a single shear zone crossing each sample. The angle of the failure plane varied from $44.3^{\circ}$ 
to $55.4^{\circ}$. The biggest internal friction angle procured in the present study belonged to the mixture of $14 \%$ of zeolite and $5 \%$ of lime $\left(55.4^{\circ}\right)$.

Finally, the results presented in the current study could be a useful reference in the stabilization of saturated sand deposits in areas near to lakes, rivers, and coastal cities susceptible to earthquakes. Further detailed investigation into the coupled effect of pozzolanic cementation and induced pore water pressure on pore space alteration is required prior to any provision of stabilization plans. It is also recommended that a comparative study should be carried out to highlight the effectiveness of accelerated curing on stabilized samples at high temperatures, and the long term consistency of stabilized soils under different deformation mechanisms and loading schemes.

Acknowledgements: The authors would like to thank Afrand Tooska Company for providing standardized testing material and A.N.S. Laboratories for providing testing machineries and equipment, with special thanks to Dr. Tim Länsivaara of Tampere University, Finland, for his comments and several valuable discussions. In addition, no specific funding was granted to this research except for the stated privileges provided by A.N.S. and Afrand Tooska Companies. We also would like to appreciate the valuable comments offered by the anonymous reviewers in improving our manuscript.

\section{REFERENCES}

1. Ferreti, G, Dario, G, Faccini, B and Coltorti, M 2018. Mitigation of sodium risk in a sandy agricultural soil by the use of natural zeolites. Environmental monitoring and assessment 190(11), 646.

2. Wen, J, Peng, Z, Liu, Y, Fang, Y, Zeng, G and Zhang, S 2018. A case study of evaluating zeolite, $\mathrm{CaCO}_{3}$, and $\mathrm{MnO}_{2}$ for Cd-contaminated sediment reuse in soil. Journal of soils and sediments 18, 323-332.

3. Kanchikeri, MM, Mukhopadhyay, R, Paul, R, Datta, S, Kumararaja, P and Sarkar, B 2019. Clay minerals and zeolites for environmentally sustainable agriculture. In Modified Clay and Zeolite Nanocomposite Materials 1, 309329.

4. Idriss, IM and Boulanger, RW 2008. Soil liquefaction during earthquakes. Earthquake Engineering Research Institute. 
5. Jamhiri, B and Parsaeimaram, M 2019. Study on Integrated Liquefaction Hazard Mapping Developed by SPT, CPT, Downhole and LPI Index. Geological Behavior (GBR) 3(2), 6-14.

6. Skempton, AW 1954. The Pore Pressure Coefficients A and B. Geotechniques 4(4), 143-147.

7. Shon, C and Young-Su K 2013. Evaluation of West Texas natural zeolite as an alternative of ASTM Class F fly ash. Construction and Building Materials 47, 389-396.

8. Seraj, R, Ferron, D and Juenger, M 2016. Calcining natural zeolites to improve their effect on cementitious mixture workability. Cement and Concrete Research 85, 102-110.

9. MolaAbasi, H, Saberian, M and Li, J 2019. Prediction of compressive and tensile strengths of zeolite-cemented sand using porosity and composition. Construction and Building Materials 202, 784-795.

10. MolaAbasi, H, Kordtabar, B and Kordnaeij, A 2017. Parameters controlling the strength of zeolite-cement-sand mixture. International Journal of Geotechnical Engineering 11(1), 72-79.

11. Yen Thi, T, Lee, J, Kumar, P, Kim, K and Sang Soo Lee 2018. Natural zeolite and its application in concrete composite production. Composites Part B: Engineering 165, 354-364.

12. Elettra, P, Medri, V, Amari, S, Manaud, J, Benito, P, Vaccari, A and Landi, E 2018. Zeolite-geopolymer composite materials: Production and characterization. Journal of cleaner production 171, 76-84.

13. Chiara, G, Mobili, QL, Yu, HJ, Brouwers, H, Ruello, ML and Tittarelli, F 2019. Properties of multifunctional lightweight mortars containing zeolite and natural fibers. Journal of Sustainable Cement-Based Materials 8(4), 214-227.

14. Xu, W, Chen, J, Wei, J, Zhang, B, Yuan, X, Xu, P, Yu, Q and Ren, R 2019. Evaluation of inherent factors on flowability, cohesiveness and strength of cementitious mortar in the presence of zeolite powder. Construction and Building Materials 214, 61-73.

15. Jamhiri, B 2020. Evaluation of pozzolan-lime stabilization on the physical properties of fine sandy engineering fills. Konya Mühendislik Bilimleri Dergisi 8(1), 80-90. 
16. Bentz, P, Ferraris, CF, Galler, M, Hansen, A and Guynn, J 2012. Influence of particle size distributions on yield stress and viscosity of cement-fly ash pastes. Cement and Concrete Research 42(2), 404-409.

17. Consoli, NC, Da Rocha, CG and Silvani, C 2013. Effect of curing temperature on the strength of sand, coal fly ash, and lime blends. Journal of Materials in Civil Engineering 26(8), 06014015.

18. Consoli, NC, Domingos, P, Prietto, M, Carraro, JAH and Heineck, KS 2001. Behavior of compacted soil-fly ash-carbide lime mixtures. Journal of Geotechnical and Geoenvironmental Engineering 127(9), 774-782.

19. Consoli, NC, Dalla Rosa, A and Saldanha, RB 2011. Variables governing the strength of compacted soil-fly ash-lime mixtures. Journal of Materials in Civil Engineering 23(4), 432-440.

20. Consoli, NC, Da Silva, LL, Dalla Rosa, A and Masuero, JR 2013. The strength of soil-industrial by-products-lime blends. Proceedings of the Institution of Civil Engineers-Geotechnical Engineering 166(5), 431-440.

21. Nagrockiene, D and Giedrius, G 2016. Research into the properties of concrete modified with natural zeolite addition. Construction and Building Materials 113, 964-969.

22. Tydlitát, VT, Zákoutský, J and Černý, R 2014. Early-stage hydration heat development in blended cements containing natural zeolite studied by isothermal calorimetry. Thermochimica Acta 582, 53-58.

23. Chan, S and X, Ji 1999. Comparative study of the initial surface absorption and chloride diffusion of high-performance zeolite, silica fume and PFA concretes. Cement and Concrete Composites 21(4), 293-300.

24. Sabet, F, Libre, A and Shekarchi, M 2013. Mechanical and durability properties of self-consolidating high-performance concrete incorporating natural zeolite, silica fume and fly ash. Construction and Building Materials 44, 175-184.

25. Liguori, B, Iucolano, F, Gennaro, B, Marroccoli, M and Caputo, D 2015. Zeolitized tuff in environmentally friendly production of cementitious material: Chemical and mechanical characterization. Construction and Building Materials 99 272-278.

26. Jamhiri, B, Ebrahimi, A and Xu, Y 2020. Investigating uncertainties in the source-site and the model-input within reliability-based deterministic and probabilistic liquefaction initiation analyses. Disaster Advances 13(2), 5562. 
27. Rao, S, N and Rajasekaran, G 1996. Reaction products formed in limestabilized marine clays. Journal of geotechnical engineering 122(5), 329336.

28. Al-Mukhtar, M, Lasledj, A and Alcover, J 2010. Behaviour and mineralogy changes in lime-treated expansive soil at $20 \mathrm{C}$. Applied clay science 50(2), 191-198.

29. Mertens, G, Snellings, R, Van Balen, K, Bicer-Simsir, B, Verlooy, P and Elsen, J 2009. Pozzolanic reactions of common natural zeolites with lime and parameters affecting their reactivity. Cement and Concrete Research 39(3), 233-240.

30. Thomas, J, Rothstein, D, Jennings, H and Christensen, B 2003. Effect of hydration temperature on the solubility behavior of $\mathrm{Ca}-, \mathrm{S}-, \mathrm{Al}-$, and $\mathrm{Si}-$ bearing solid phases in Portland cement pastes. Cement and Concrete Research 33(12), 2037-2047.

31. Namikawa, T, Shota, H, Yoshiya, A and Taihei, S 2017. Failure behavior of cement-treated soil under triaxial tension conditions. Soils and Foundations 57(5), 815-827.

32. Nataatmadja, A and AK, Parkin 1989. Characterization of granular materials for pavements. Canadian Geotechnical Journal 26(4), 725-730.

33. Barton, N 1993. Physical and discrete element models of excavation and failure in jointed rock. Assessment and Prevention of Failure Phenomena in Rock Engineering, Turkish National Society for Rock Mechanics, Istanbul, Balkema, Rotterdam, 35-46.

34. Wang, YH and Leung, SC 2008. A particulate-scale investigation of cemented sand behavior. Canadian Geotechnical Journal 45(1), 29-44.

35. Zhao, B, Liu, D, Huang, T, Huang, W and Liu, W 2017. Mechanical Behavior of Red Sandstone under Incremental Uniaxial Cyclical Compressive and Tensile Loading. Shock and Vibration 10, 1-10.

36. Finge, Z, Doanh, T and Dubujet, P 2006. Undrained anisotropy of Hostun RF loose sand: new experimental investigations. Canadian geotechnical journal, 43(11), 1195-1212.

37. Haeri, SM, Hamidi, A and Tabatabaee, N 2005. The effect of gypsum cementation on the mechanical behavior of gravely sands. Geotechnical Testing Journal 28(4), 380-390. 
38. Hamidi, A and Haeri, SM 2008. Stiffness and deformation characteristics of a cemented gravely sand. International Journal of Civil Engineering 6(3), 159-173.

39. Rios, S, da Fonseca, A and Baudette, B 2014. On the shearing behaviour of an artificially cemented soil. Acta Geotechnica 9(2), 215-226.

40. Duda, M and Renner, J 2012. The weakening effect of water on the brittle failure strength of sandstone. Geophysical Journal International 192(3), 1091-1108.

41. Desrues, J, Chambon, R, Mokni, M and Mazerolle, F 1996. Void ratio evolution inside shear bands in triaxial sand specimens studied by computed tomography. Géotechnique 46(3), 529-546.

42. Baldino, N, Gabriele, D, Lupi, FR, Seta, L and Zinno, R 2014. Rheological behaviour of fresh cement pastes: Influence of synthetic zeolites, limestone and silica fume. Cement and Concrete Research, 63, 38-45.

43. Poon, CS, Lam, L, Kou, SC and Lin, ZS 1999. A study on the hydration rate of natural zeolite blended cement pastes. Construction and Building Materials 13(8), 427-432.

44. Ahmadi, B and Shekarchi, M 2010. Use of natural zeolite as supplementary cementitious material. Cement and Concrete Composites 32(2), 134-141.

45. Juenger, $M$ and Siddique, $R$ 2015. Recent advances in understanding the role of supplementary cementitious materials in concrete. Cement and Concrete Research 78, 71-80.

46. Cai, Y, Shi, B, WW Ng, B and Tang, C 2006. Effect of polypropylene fibre and lime admixture on engineering properties of clayey soil. Engineering geology 87(4), 230-240.

47. Muntohar, AS, Widianti, A, Hartono, E and Diana, W 2013. Engineering properties of silty soil stabilized with lime and rice husk ash and reinforced with waste plastic fiber. Journal of Materials in Civil Engineering 25(9), 1260-1270.

48. Consoli, NC, Dalla Rosa, J, Gauer, EA, Dos Santos, VR, Moretto, RL and Corte, MB 2012. Key parameters for tensile and compressive strength of silt-lime mixtures. Géotechnique Letters 2(3), 81-85.

49. Consoli, NC, Festugato, L, Scapini Consoli, B and Da Silva, LL 2014. Assessing failure envelopes of soil-fly ash-lime blends. Journal of Materials in Civil Engineering 27(5), 04014174. 
50. Tatsuoka, F, Sachio, M, Kenzo, O and Fujii, S 1986. Prediction of cyclic undrained strength of sand subjected to irregular loadings. Soils and Foundations 26(2), 73-90.

51. Wissa, Anwar, EZ and Charles C, Ladd 1965. Shear strength generation in stabilized soils. Massachusetts Inst of Tech Cambridge Soil Mechanics Div, No. RR-R65-17.

52. Lee, KL, Morrison, RA and Haley, SC 1969. A note on the pore pressure parameter B. In Proceedings of the 7th International Conference of Soil Mechanics and Foundation Engineering 1, 231-238.

53. Berge, PA, Wang, HF and Bonner, BP 1993. Pore pressure buildup coefficient in synthetic and natural sandstones. In International journal of rock mechanics and mining sciences \& geomechanics abstracts 30(7), 1135-1141.

54. Green, D and Wang, H 1986. Fluid pressure response to undrained compression in saturated sedimentary rock. Geophysics 51(4), 948-956.

55. Fredrich, JT. Martin, JW and Clayton, R. B 1995. Induced pore pressure response during undrained deformation of tuff and sandstone. Mechanics of Materials 20(2), 95-104.

56. Jongpradist, P, Youwai, S and Jaturapitakkul, C 2011. Effective void ratio for assessing the mechanical properties of cement-clay admixtures at high water content. Journal of geotechnical and geoenvironmental engineering 137(6), 621-627. 